\section{Percepção das mães sobre o cuidado do bebê de baixo peso antes e após implantação do Método Mãe-Canguru em hospital público da cidade de São Paulo, Brasil}

\section{Maternal perception of low birth weight babies before and following the implementation of the Kangaroo Mother Care in a public hospital, in the city of São Paulo, Brazil}

Tereza Setsuko Toma 1

Sonia Isoyama Venâncio 2

Daniela de Almeida Andretto 3

\footnotetext{
1-3 Instituto de Saúde. Secretaria de Estado da Saúde de São Paulo. Rua Santo Antonio, 590, 2. andar. São Paulo, SP, Brasil. CEP: 01.314-000. E-mail: ttoma@isaude.sp.gov.br
}

\begin{abstract}
Objectives: increase the understanding of the different ways low income families deal with a preterm baby aiming at the improvement of the Kangaroo Mother Care (KMC).

Method: qualitative study performed in the city of São Paulo, State of São Paulo, in 2004 with the interview of 19 mothers before and 22 mothers following the implementation of the KMC. The design of the interviews included open questions to obtain information on how mothers tended their low weight babies, household arrangements and other measures they resorted to. The Grounded Theory Method Approach was used for analysis.

Results: the need to care for other children seems to be one of the main KMC constraints. In comparison to mothers interviewed before the program's implementation, the mothers using the KMC were younger, had more schooling, no other children and reported less difficulty in breastfeeding their babies.

Conclusions: the KMC offer in a maternity in the outskirts of São Paulo reflects positive effects on breastfeeding. The tendency of nuclear families hinders women's participation in the program. Awareness of the limitations and possibilities of each family may contribute to improve the program's implementation.

Key words Low weight newborn babies, Humane care, Breast feeding, Family relations, Qualitative analysis
\end{abstract}

\section{Resumo}

Objetivos: aumentar a compreensão sobre os diferentes modos que as famílias de baixa renda lidam com o nascimento de um bebê pré-termo, com vistas a aprimorar a implantação do Método Mãe-Canguru (MMC).

Método: estudo qualitativo realizado em São Paulo, estado de São Paulo, em 2004, no qual foram entrevistadas 19 mães antes e 22 mães após implantação do MMC. O roteiro de entrevistas incluía questões abertas, das quais emergiram as informações sobre como as mães cuidaram de seus bebês de baixo peso, os arranjos domésticos e outras medidas a que recorreram. Para análise utilizou-se a abordagem da Grounded Theory.

Resultados: a necessidade de cuidar de outros filhos parece ser um dos principais limitadores para a opção ao MMC. Em comparação às mães entrevistadas antes da implantação do programa, as mães-cangurus eram mais jovens, mais escolarizadas, sem outros filhos, recebiam mais ajuda nas tarefas domésticas $e$ relataram menos dificuldades na amamentação.

Conclusões: a oferta do MMC em uma maternidade da periferia de São Paulo sugere efeitos positivos sobre a amamentação. A tendência à conformação de famílias nucleares dificulta a participação das mulheres no programa. Conhecer as limitações e possibilidades de cada família pode contribuir para o aperfeiçoamento do processo de implantação.

Palavras-chave Recém-nascido de baixo peso, Humanização da assistência, Aleitamento materno, Relações familiares, Análise qualitativa 


\section{Introdução}

O Método Mãe-Canguru (MMC) é uma modalidade de cuidado ao recém-nascido de baixo peso que tem recebido cada vez mais atenção da comunidade científica em todo o mundo. Se, por um lado, o método tem sido analisado como tecnologia apropriada capaz de garantir a sobrevivência dos bebês em locais com escassez de recursos, ${ }^{1,2}$ por outro, tem despertado o interesse de estudiosos dos países desenvolvidos, que manifestam a preocupação com a qualidade de vida das crianças nascidas prematuramente, especialmente aquelas com menos de 1500g. ${ }^{3}$ Nesses locais, o MMC se inclui no rol de intervenções que poderiam contribuir para um ótimo desenvolvimento neuro-comportamental, tais como a sucção não-nutritiva, a massagem, a prevenção e tratamento da dor e o Newborn Individualized Development Care and Assessment Program (NIDCAP). 4

A proposta surgida na Colômbia há mais de 25 anos ainda é vista com muita cautela por médicos e elaboradores de políticas. 5 Estudos são necessários, particularmente sobre custo-efetividade e limitações da aplicação em diferentes localidades. Entretanto, as evidências científicas disponíveis indicam que o método apresenta os atributos básicos exigidos para a incorporação de uma nova tecnologia no setor saúde - segurança, baixo custo e adaptabilidade a contextos socioculturais diversos. 1,6-9

O MMC tem sido apoiado em vários países como uma das ações dentro das políticas de atenção neonatal.3,5 Entretanto são raros os exemplos, como o do Brasil, em que iniciativas voltadas especificamente para sua implementação por meio do sistema de saúde foram conduzidas de forma sistemática. 10 Em 2000, o Ministério da Saúde lançou as diretrizes do método oferecendo parâmetros para a implantação de cada uma de suas etapas - unidade neonatal, alojamento canguru e canguru ambulatorial/domiciliar.11 Nos dois anos seguintes, um projeto de disseminação envolvendo Ministério da Saúde, Banco Nacional de Desenvolvimento Econômico e Social (BNDES) e Fundação ORSA, viabilizou a realização de seminários e o estabelecimento de centros de referência regionais, assim como a capacitação de equipes de grande parte das unidades neonatais do país. 8

Contudo, profissionais motivados por cursos ou palestras muitas vezes não sabem por onde começar e podem sucumbir frente a dificuldades que lhes parecem intransponíveis. Também, não se pode ignorar o quanto o nascimento de um bebê de baixo peso e/ou pré-termo impõe dificuldades às famílias.
Diferentemente de uma criança nascida a termo, com freqüência, o bebê de baixo peso será separado de sua mãe e permanecerá internado por um tempo prolongado. As conseqüências dessa separação para o cuidado apropriado do bebê de baixo peso dependem das facilidades oferecidas pelo serviço de saúde, mas também das estratégias adotadas pelas famílias. ${ }^{12}$

Um estudo de avaliação envolvendo 28 hospitais do Estado de São Paulo, cujas equipes passaram pelos cursos do Ministério da Saúde até o ano de 2002, mostrou que os serviços se encontram em estágios bastante heterogêneos de implantação do programa. As dificuldades relatadas pelas equipes são de naturezas diversas, assim como as medidas utilizadas para superá-las. Como medidas facilitadoras para o processo de implantação foram identificados o fato de ser hospital-escola, ter sido credenciado como Hospital Amigo da Criança, dispor de Banco de Leite Humano e contar com mais de 12 profissionais capacitados. A dificuldade das equipes dos hospitais em lidar com as famílias emerge como uma das possíveis barreiras para a implantação de todas as etapas previstas para o programa. ${ }^{13}$

Espera-se com este estudo contribuir para a implementação do MMC nas unidades do Sistema Único de Saúde, a partir da compreensão sobre o modo de operar das famílias de baixa renda em face do nascimento de um bebê pré-termo.

\section{Métodos}

Este estudo é parte de um projeto matriz14 cujo objetivo foi avaliar o impacto da implantação do MMC sobre a evolução clínica e o desenvolvimento neuropsicoafetivo de recém-nascidos pré-termo e de baixo peso em um hospital público. O Hospital Municipal do Campo Limpo é unidade de referência para atendimento de mulheres com gestações de alto risco da região Sul da cidade de São Paulo, Brasil, e realiza cerca de 350 partos ao mês, dos quais $12 \%$ resultam em recém-nascidos com baixo peso $(<2500 \mathrm{~g})$. O projeto foi realizado de janeiro 2004 a maio de 2005 Nesse período, além de contar com um serviço de Banco de Leite Humano, o hospital encontrava-se em franco processo de implantação dos Dez Passos para o Sucesso da Amamentação preconizados pela Iniciativa Hospital Amigo da Criança. A estratégia de implantação do MMC incluiu um planejamento conjunto da direção do hospital com as chefias médica e de enfermagem, a preparação de um grupo de dez profissionais da unidade neonatal mediante curso de capacitação de 40 horas, a capacitação de 
cerca de $80 \%$ dos integrantes da equipe, distribuídos em quatro cursos com carga horária de 20 horas, além de treinamento em serviço e supervisão técnica. Equipes do Programa Saúde da Família da região também receberam informações, por meio de cursos com 16 horas de duração.

Duas coortes de bebês nascidos com menos de $2000 \mathrm{~g}$, que permaneceram pelo menos uma semana na unidade neonatal e cujas mães aceitaram participar do estudo, foram acompanhadas por um período de seis meses. Da primeira coorte participaram bebês que receberam alta hospitalar de 1 de fevereiro a 21 de abril de 2004, período anterior ao início da implantação do programa. A segunda coorte foi composta de bebês participantes do MMC e que receberam alta de 10 de agosto a 29 de novembro de 2004.

Para a finalidade deste estudo qualitativo, tratase de um grupo de conveniência, uma vez que ele não foi formado por meio da técnica de saturação ou recorrência dos dados, conforme preconizado. 15 As mães dos bebês das duas coortes foram convidadas para a realização de duas entrevistas, a primeira às vésperas da alta hospitalar do bebê e a segunda no retorno ambulatorial em torno de 15 a 30 dias após a alta. A primeira entrevista foi feita com 19 mulheres antes da implantação e 22 após a implantação do programa (mães-cangurus). Houve perda de seguimento de uma mulher em cada grupo, sendo a segunda entrevista realizada com 18 mães antes da implantação e 21 mães-cangurus.

As entrevistas foram realizadas por meio de um roteiro contendo três questões abertas, nas quais se solicitava que a entrevistada falasse livremente sobre a gestação, o parto e os períodos hospitalar e domiciliar após o parto. O roteiro trazia um lembrete sobre tópicos que as entrevistadoras deveriam explorar em cada uma das questões, caso eles não surgissem espontaneamente.

Cada entrevista durou de 8 a 35 minutos. Elas foram gravadas e, posteriormente, transcritas.

As entrevistas foram realizadas por duas das autoras, que procuraram manter um padrão semelhante de coleta dos dados por meio da escuta e discussão das entrevistas iniciais.

Buscou-se realizar as entrevistas em ambiente com privacidade, silencioso e isento de interferências externas, entretanto as condições ideais nem sempre foram alcançadas. A falta de uma sala exclusiva para esse tipo de atividade fez com que a cada entrevista houvesse a necessidade de identificar um espaço disponível, às vezes uma enfermaria vazia, outras vezes o Banco de Leite Humano ou salas de consulta no ambulatório.
Alguns dados sobre a caracterização das mulheres e dos bebês foram obtidos a partir dos registros do projeto matriz.

O trabalho de análise foi feito de forma convencional, por meio do programa Word for Windows, em que os temas e trechos das falas identificados como relevantes receberam marcações com cores diferentes.

A análise efetivou-se em três etapas: a) uma leitura livre das falas levou à definição das categorias centrais; b) uma leitura axial buscou semelhanças e contrastes dentro de cada uma das categorias centrais; e c) uma leitura seletiva e construção de diagramas contribuíram para a emergência do processo explicativo. ${ }^{16,17}$

Para facilitar as leituras foram construídos quadros, nos quais trechos das falas foram recortados e colados, conforme os seguintes temas: visitas ao bebê internado, cuidados propiciados ao bebê, participação no MMC, composição das famílias, apoio do companheiro e de outros membros da família, situação de trabalho fora de casa e/ou estudo das mulheres participantes.

A Figura 1 apresenta o modelo utilizado para sistematizar a análise dos dados que teve como referência a Grounded Theory, 16,17 abordagem que propiciou a interpretação de como a relação entre os fatores individuais, familiares e as facilidades oferecidas pelos serviços de saúde pode influenciar o cuidado do recém-nascido de baixo peso. Conforme Cassiani et al. (1996: 78)16 a Grounded Theory ou teoria fundamentada nos dados refere-se a:

[...] modo de construir indutivamente uma teoria

assentada nos dados, através da análise qualitativa

destes e que, agregada ou relacionada a outras teorias,

poderá acrescentar ou trazer novos conhecimentos à área do fenômeno. Seguindo-se aos princípios da metodologia qualitativa, a teoria fundamentada nos dados é uma metodologia de campo que objetiva gerar construtos teóricos que explicam ação no contexto social sob estudo. O investigador procura processos que estão acontecendo na cena social, partindo de uma série de hipóteses, que, unidas uma às outras, podem explicar o fenômeno, combinando abordagens indutivas e dedutivas.

O projeto matriz foi aprovado pelos Comitês de Ética em Pesquisa do hospital em que foi realizado e do Instituto de Saúde da Secretaria de Estado da Saúde de São Paulo.

As participantes receberam informações orais e por escrito e assinaram um termo de consentimento durante a fase de captação para o projeto matriz. Antes de entrevistá-las para este estudo, novamente foram informadas sobre o projeto e a finalidade das entrevistas, reiterando-se oralmente o consentimento. Isso 
Modelo paradigmático utilizado para a sistematização da análise. São Paulo, Capital, 2004.

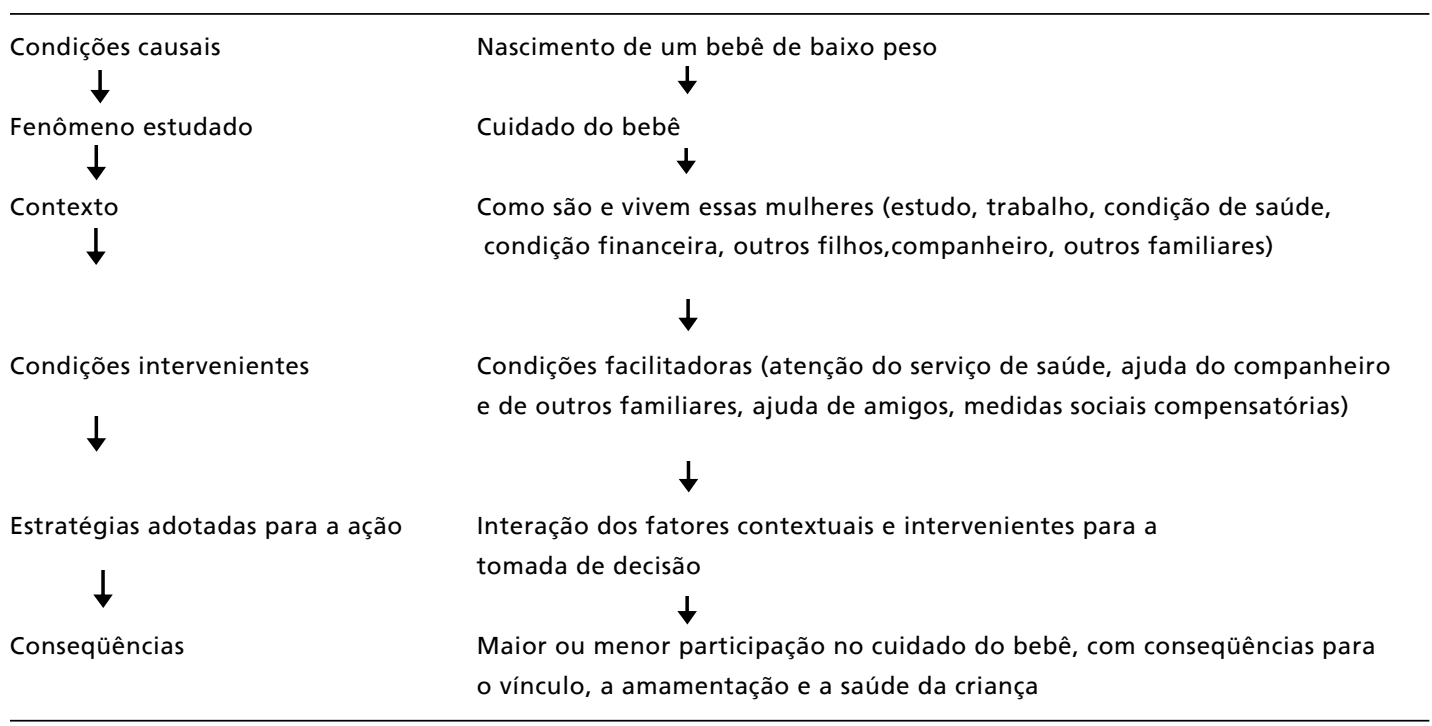

foi necessário porque, na maioria das vezes, antes da entrevista elas haviam passado por etapas paralelas do projeto realizadas por outros pesquisadores.

Após a transcrição, as mulheres passaram a ser identificadas por códigos - M1 a M19 para as mães antes da implantação e MC1 a MC22 para as mãescangurus. Não houve qualquer incentivo financeiro para sua participação, a não ser o fornecimento de passes de ônibus e lanches.

\section{Resultados}

Os resultados a seguir são apresentados de acordo com os temas relevantes que emergiram durante a análise das falas transcritas.

Os dados sobre caracterização das mães e seus bebês apresentados, respectivamente, nas Tabelas 1 e 2 são provenientes do projeto matriz, com exceção das informações sobre o aleitamento materno após a alta hospitalar.

A maioria das mães de ambos os grupos é parda, mora com o companheiro e tem renda familiar até três salários mínimos (Tabela 1). Devido à gravidez atual, emprego e estudo foram interrompidos, respectivamente, por sete mães antes da implantação e oito mães-cangurus. As mães-cangurus tendem a ser mais jovens, mais escolarizadas, sem outros filhos e representam cerca de $40 \%$ das mães de bebês de baixo peso atendidas pelo hospital após a implan- tação do MMC.

Com relação aos bebês, houve um par de gêmeos antes da implantação e dois pares cangurus; as características entre os dois grupos quase não diferem, exceto quanto ao tipo de alimentação na alta hospitalar (Tabela 2).

Praticamente todas as mulheres, de ambos os grupos, visitavam diariamente suas crianças internadas na unidade neonatal. Em geral permaneciam pelo menos seis horas junto aos bebês e lhes ofereciam os seguintes cuidados: conversar, acarinhar, olhar, trocar fraldas, pegar no colo, cheirar, abraçar e amamentar. Quase metade das mães, de ambos os grupos, relatou ter praticado a posição canguru na unidade neonatal, porém nenhuma delas banhou o bebê, prática exclusiva do corpo de enfermagem.

[...] bem eu troco, dou carinho, ela mama, converso com ela até a hora de eu ir embora. Já tive vontade (de dar banho), mas não dei. Ah aqui a norma é os enfermeiros, eles é que dão o banho. Não quando as crianças nascem assim de um peso normal, aí elas vão para o quarto, aí as mães ficam cientes que são elas que vão cuidar. (M1,

31 anos, outros filhos de 2, 5, 9, 10, 12 e 14 anos, mora com o companheiro)

Após a implantação do programa, as mulheres que optaram pelo método Mãe-Canguru permaneciam em quartos que abrigavam até dois pares mãebebê. As falas mostram o lado positivo do MMC em expressões como "é gostoso ficar juntinho"; "sabe o que está acontecendo o tempo todo"; "fica aqueci- 
Características das mães antes da implantação e mães-cangurus participantes do estudo. São Paulo, Capital, 2004.

\begin{tabular}{|c|c|c|}
\hline Características & Mães antes da implantação $(n=19)$ & Mães-cangurus $(n=22)$ \\
\hline \multicolumn{3}{|l|}{ Idade (anos) } \\
\hline Média (min - max) & $26(16-41)$ & $24(15-39)$ \\
\hline Até 20 anos & 5 & 10 \\
\hline \multicolumn{3}{|l|}{ Cor } \\
\hline Branca & 4 & 8 \\
\hline Preta & 1 & 2 \\
\hline Parda & 14 & 12 \\
\hline \multicolumn{3}{|l|}{ Escolaridade (anos completos) } \\
\hline 1 a 4 & 8 & 6 \\
\hline 5 a 8 & 8 & 7 \\
\hline 9 a 11 & 3 & 9 \\
\hline \multicolumn{3}{|l|}{ Tem outros filhos } \\
\hline Não & 6 & 13 \\
\hline Sim & 13 & 9 \\
\hline \multicolumn{3}{|l|}{ Com quem mora } \\
\hline Companheiro & 14 & 14 \\
\hline Pais, sogros ou outros familiares & 4 & 8 \\
\hline Amiga & 1 & - \\
\hline \multicolumn{3}{|c|}{ Renda mensal da família (salários mínimos) } \\
\hline Até 1 & 4 & 1 \\
\hline 1,1 a 3 & 10 & 16 \\
\hline 3,1 e mais & 4 & 3 \\
\hline Sem informação & 1 & 2 \\
\hline
\end{tabular}

Fonte: Venâncio SI et al. Diagnóstico da evolução de recém-nascidos do Hospital do Campo Limpo, São Paulo; 2005.14

dinha, mais protegida"; "ajuda a mamar"; "está mais gordinha, esperta"; "está mais coradinha, a segurança é maior"; Por outro lado, com frequiência aparecem também queixas do tipo "o difícil é que eu fiquei longe da outra (filha que está em casa)"; "me incomodava ficar sem ir para casa"; "machuca as costas, tem que ficar deitada, estou querendo ir embora"; "é cansativo, mas fazer o quê"; "hospital chato, umas pessoa fala uma coisa e outras fala outra"; "à noite é meio cansativo, toda hora acorda, não gosto de dormir de barriga para cima"; "tem hora que ela não quer ficar, ela começa a subir, sair por cima".

A maioria dos companheiros das mulheres de ambos os grupos estavam empregados. Em geral, os companheiros das mães antes da implantação do programa costumavam acompanhá-las nas visitas ao bebê apenas nos finais de semana e nas folgas do trabalho. Várias mães-cangurus, por sua vez, relataram que seus companheiros sempre as acompanhavam nas visitas ao bebê e passaram a visitá-las diariamente no alojamento canguru. Nesse grupo, mesmo as solteiras recebiam visitas freqüentes de seus namorados.

No momento da entrevista, todas amamentavam. Entretanto, nota-se uma diferença substancial entre os relatos das mães antes da implantação e as mãescangurus.

Entre as mães antes da implantação, a maioria referiu que seus bebês recebiam complementação da mamada com leite materno ordenhado e/ou fórmula infantil. Várias delas referiram algum grau de dificuldade com a amamentação, tal como ter pouco leite, o leite estar secando e o bebê não sugar bem ou mamar devagar. Apenas quatro referiram que os bebês mamavam bem. A maioria realizava a ordenha das mamas e algumas chegaram a tomar medica- 
Características dos bebês antes da implantação e bebê-Cangurus participantes do estudo. São Paulo, Capital, 2004.

\begin{tabular}{|c|c|c|}
\hline Características & Bebês antes da implantação $(n=20)$ & Bebês-canguru $(n=23)$ \\
\hline \multicolumn{3}{|l|}{ Sexo } \\
\hline Feminino & 12 & 13 \\
\hline Masculino & 8 & 10 \\
\hline Bebês gemelares (par) & 1 & $2 *$ \\
\hline \multicolumn{3}{|l|}{ Idade gestacional (semanas e dias) } \\
\hline Média (min - max) & $33,2(30-38,4)$ & $34,1(29,4-38)$ \\
\hline \multicolumn{3}{|l|}{ Peso ao nascer $(\mathrm{g})$} \\
\hline Média (min - max) & $1609(1200-2180)$ & $1678(1015-2050)$ \\
\hline \multicolumn{3}{|l|}{ Peso na alta (g) } \\
\hline Média (min - max) & $2015(1775-2250)$ & $1999(1830-2160)$ \\
\hline \multicolumn{3}{|l|}{ Duração da internação (dias) } \\
\hline Média (min - max) & $30(7-57)$ & $27(7-81)$ \\
\hline \multicolumn{3}{|l|}{ Tipo de alimentação na alta } \\
\hline Seio materno & - & 19 \\
\hline Seio materno e fórmula infantil & 20 & 4 \\
\hline \multicolumn{3}{|c|}{ Peso de início do Método Mãe-Canguru (g) } \\
\hline Média (min - max) & - & $1774(1600-1970)$ \\
\hline \multicolumn{3}{|c|}{ Idade de início do Método Mãe-Canguru (dias) } \\
\hline Média (min - max) & - & $18(0-74$ \\
\hline \multicolumn{3}{|c|}{ Duração do Método Mãe-Canguru intra-hospitalar (dias) } \\
\hline Média (min - max) & - & $9(5-18)$ \\
\hline \multicolumn{3}{|l|}{ Tipo de alimentação em casa** } \\
\hline Seio materno & 5 & 13 \\
\hline Seio materno + água e chá & 1 & 3 \\
\hline Seio materno + leite de vaca & 9 & 4 \\
\hline Leite de vaca & 3 & 2 \\
\hline Sem informação & 1 & - \\
\hline
\end{tabular}

* Um dos gêmeos não participou do programa; ** Dados obtidos na segunda entrevista, com perda de uma mulher em cada grupo. A falta de informação refere-se a uma mulher entrevistada tardiamente.

Fonte: Venâncio SI et al. Diagnóstico da evolução de recém-nascidos do Hospital do Campo Limpo,. São Paulo; 2005.14 
mento para aumentar a produção do leite.

Quando eu estou aqui que ele pega o peito só um pouquinho eu falo para elas dar o leite para ele, para elas completar. Ele não mama muito não. Estou tirando. Estava secando, aí elas passaram um remédio para mim tomar, aí está voltando. Eu estou tirando de três em três horas. Eu espero o vidrinho encher, aí quando enche eu trago. Elas dão no copinho. (M18, 16 anos, primeiro filho, mora com os pais)

Entre as mães-cangurus, apenas uma referiu dificuldade para amamentar. Durante a fase de internação na unidade neonatal, cerca de um terço dos bebês-cangurus também receberam complementação da mamada com leite materno ordenhado e/ou fórmula infantil. Quase todas as mães-cangurus referiram ordenhar as mamas. A riqueza de detalhes sobre as orientações recebidas chama a atenção, conforme pode ser visto nessas falas:

[...] ele mama muito bem. É, só o peito. ... Eu sempre deixava, tirava lá em casa e trazia prá cá. É só primeiro lavar bem as mãos, depois colocar a touca, aquela proteçãozinha aqui do nariz, depois é fazer massagem ao redor dos seios até sair um pouquinho de leite ... Aí ia tirando com os quatro dedos em baixo e o polegar em cima. Aí apertando prá trás, ... tipo sugando, como se fosse a criança sugando. (MC14, 21 anos, primeiro filho, mora com o companheiro)

[...] só o seio. Já fui orientada que ela não precisa mais nada a não ser o seio. A enfermeira me orientou tudo. Ah, a higiene que tem que ter e os cuidados, colocar toquinha, colocar o negócio no rosto, a máscara, e quando tirar, congela e retirar num copinho diferente e este-rilizado e tá colocando dentro daquele vidrinho e tá trazendo pro banco ... eu tirava em casa e eu tirava aqui também. (MC16, 35 anos, outros filhos de 5 e 10 anos, mora com o companheiro)

Poucas mulheres relataram não contar com qualquer ajuda, entretanto entre as mães-cangurus foi mais freqüente a ajuda substancial nas tarefas domésticas.

Em ambos os grupos nota-se que as mulheres que vivem junto com os pais, sogros, outros parentes ou amigos contam com arranjos mais favoráveis, uma vez que as tarefas domésticas costumam ser realizadas pela dona da casa ou compartilhadas entre os moradores.

[..] Ela arruma o quarto dela e passa a roupa, aí eu arrumo o meu quarto e arrumo a cozinha e lavo o banheiro.

Aí, tipo assim, quando ela lava a roupa eu passo, às vezes sabe eu lavo roupa e ela passa. (M5, 19 anos, outro filho de um ano, mora com os tios).

A maioria das mães de ambos os grupos referiu receber ajuda de seus companheiros, tais como limpar a casa, cozinhar, lavar e passar roupas. Muitas vezes, elas costumam antecipar ou adiar as tarefas para visitar o bebê, conforme relato:

Assim, ele não é de ajudar muito não. Serviço de casa não é o tipo dele não. Mas quando eu preciso ele ajuda ... Ah, eu faço tudo à noite quando eu chego às sete horas, trabalho até 11 horas até meia noite e depois no outro dia levanto cedo. (M3, 41 anos, outro filho de nove anos, mora com o companheiro)

Esse tipo de sobrecarga é amenizada quando podem contar com a ajuda adicional dos parentes consangüíneos, fato mais frequiente entre as mãescangurus.

[...] eh, eu levantava de manhã, fazia o que eu tinha que fazer e deixava pronto e aí eu vinha pra cá. ... tem a minha irmã que sempre me ajuda. E meu marido também às vezes me ajuda. Quando tá em casa. Ah, ele varre a casa, lava a louça, às vezes faz comida. Lava a rou-pa dele. (MC12, 33 anos, mãe de gêmeos, outros filhos de 10 e 13 anos, mora com o companheiro)

Algumas mães antes da implantação citaram que essa ajuda não estava disponível mesmo quando os parentes moravam perto, seja por motivo de doença, trabalho fora de casa ou ter sua própria casa e filhos para cuidar.

Às vezes, quem cuida da casa é uma filha ainda pré-adolescente, fato que limita o tempo que a mãe pode permanecer junto ao bebê internado.

$\mathrm{Na}$ minha casa quem cuida mesmo é a menina de 10 anos é por isso que eu não posso ficar mais tempo aqui ... ela só sai para escola depois que eu chego. Ah, ele é um bom marido, ele ajuda no que pode, não tem tempo difícil para ele no que precisar fazer ele faz, um almoço, lava roupa, limpa casa, o que for preciso ele faz. (M1, 31 anos, outros filhos de 2, 5, 9, 10, 12 e 14 anos, mora com o companheiro)

Os arranjos necessários para dar conta de outros filhos são mais complexos e envolvem com mais frequiência outros membros da família e vizinhos. Da mesma forma que as tarefas domésticas, a situação parece mais favorável quando as mães moram com seus parentes consangüíneos ou sogros. As falas a seguir mostram algumas das estratégias utilizadas pelas mães de ambos os grupos:

[...] ele está com sete anos. Às vezes quando eu venho só às 2 horas e volto à tarde, ele fica sozinho dentro de casa trancado até eu chegar. Quando eu venho e passo o dia todo, eu faço o possível para ele ir para a casa da minha sogra. Mesmo sendo difícil para o meu marido levar ele lá. É longe da minha casa para lá são quatro conduções. Esta semana mesmo ele está ficando com a minha sobrinha. Ela está em casa, não está trabalhando. Ela mora próximo da minha casa. (M6, 31 anos, outro filho de sete anos, mora com o companheiro)

[...] tá na escola. Ele vai de perua. ... pela manhã, quem cuida dele é minha mãe, e à tarde quando meu esposo chega pega ele na casa da minha mãe. (MC22, 31 anos, outro filho de sete anos, mora com o companheiro).

Os meios de transporte utilizados pelas mulheres para visitar os bebês eram ônibus ou lotação. Raras vezes, o carro foi utilizado, sendo um pouco mais citado entre as mães-cangurus. Muitas mulheres relataram a questão financeira como uma das dificul- 
dades enfrentadas. O provimento de passes de ônibus por parentes e serviços de saúde permitiu as visitas diárias por parte de algumas mães.

Eu tenho pedido passe para a assistente social. E falando nisso eu tenho que pegar passe com ela, porque eu gastei os dois passes ... aí para voltar eu só tenho um e para vir amanhã se ela não tiver os passes eu não vou ter para vir. Eu pego dois ônibus. (M13, 17 anos, primeiro filho, mora com o companheiro)

Quase metade das mulheres referiu utilizar quatro ônibus para ida e volta ao hospital. Para algumas o programa de integração entre os meios de transporte coletivo permitiu uma economia e facilitou as visitas.

A fala abaixo ilustra o esforço realizado por algumas mulheres.

Eu venho todos os dias. Às vezes eu venho a pé e às vezes eu venho de ônibus. Daqui na minha casa é uns 40 minutos. Venho sozinha. Eu venho assim tipo umas 10 horas e quando é umas cinco horas assim eu vou embora. (M17, 31 anos, outros filhos de cinco e nove anos, mora com os pais)

Três bebês antes da implantação e dois cangurus haviam sido reinternados. Os demais passaram bem de saúde. Em ambos os grupos, muitas mães referiram que seus bebês tinham cólica, não dormiam à noite, choravam ou queriam mamar toda hora. A maioria já freqüentava Posto de Saúde próximo da casa além do ambulatório ou Banco de Leite Humano do hospital. Praticamente todas receberam visita de agentes do Programa Saúde da Família que, em geral, reforçaram a necessidade de manter o acompanhamento dos bebês nas unidades de saúde.

Os bebês antes da implantação costumavam dormir no berço ou carrinho no quarto dos pais. Por outro lado, a maioria dos bebês-cangurus dormia junto com a mãe, seja em posição canguru ou na mesma cama. A maioria das mães-cangurus manteve o bebê em posição canguru por algum tempo. Poucas o fizeram de maneira contínua; em geral praticavam de acordo com sua conveniência.

Com relação às tarefas domésticas e cuidados com outros filhos, para mães de ambos os grupos houve uma tendência ao retorno às atividades cotidianas, com redução na ajuda que receberam durante a fase de internação da criança.

Chama a atenção a diferença entre os grupos com relação à alimentação das crianças (Tabela 2). Enquanto a maioria dos bebês-cangurus continuava em amamentação exclusiva, entre os bebês antes da implantação a maioria recebia leite de vaca. Nota-se nas falas que as mães antes da implantação tiveram mais dificuldade do que as mães-cangurus em manter a produção de leite materno:

No terceiro dia eu já tive que passar ele no pediatra para ele dar o leite já. Porque ela não estava sugando bem e estava chorando, então era fome né. Eu às vezes tirava e dava o leite (materno) na mamadeira mas fiquei com medo. (M3, 41anos, outro filho de nove anos, mora com o companheiro)

Ah, eu dou um ... seio só, aí da próxima mamada eu dou o outro. Ele mama bem. Ah, muitos amigos fala assim prá mim dar chá pra ele, tem uma vizinha minha que quer que eu dê chupeta pra ele, não adianta que eu não vou dar não. (MC20, 19 anos, primeiro filho, mora com a mãe)

\section{Discussão}

A entrevistadas representaram um grupo de conveniência. Entretanto, a diversidade de situações permitiu uma análise com ênfase sobre a interação entre os fatores contextuais e intervenientes.

Após a implantação do MMC, $60 \%$ das mulheres não fizeram opção pelo programa. Uma das falhas do estudo foi não ter registrado as características dessas mulheres, nem previsto a realização de entrevistas com algumas delas.

A estratégia utilizada para a implantação do programa foi abrangente, envolvendo aspectos fundamentais apontados por alguns autores, tais como a decisão do gestor, uma boa parcela de profissionais capacitados, a supervisão técnica e o monitoramento. 10,13,18,19 Além do mais, o hospital apresentava como facilitadores o serviço de Banco de Leite Humano e a implantação dos Dez Passos da Iniciativa Hospital Amigo da Criança. Na unidade de cuidados intermediários também já se permitia às mães manter seus bebês em posição canguru. Como conseqüência, em quatro meses conseguiu-se por em prática as três etapas recomendadas pela norma ministerial. 14 Esse resultado é promissor dada a complexidade do MMC e as numerosas dificuldades relacionadas à implantação do programa completo, particularmente as etapas de alojamento canguru e ambulatorial/domiciliar. 13

A adoção de critérios conservadores que limitam as possibilidades de participação das famílias, no entanto, denota a necessidade de superar o paradigma do cuidado do bebê de baixo peso. Por isso, o programa implantado deve ser encarado como um produto inacabado, em que a melhoria na qualidade da atenção passa pelo refinamento das práticas a partir da experiência que os profissionais vão gradualmente adquirindo e do monitoramento e reavaliação periódicos. $10,19,20$

Este estudo, assim como outros com abordagem qualitativa, mostra que as falas das mulheres são um importante indicador da adequação das práticas às suas necessidades e possibilidades. 12,21,22 A compre- 
ensão de seus dramas individuais passa pelo reconhecimento da necessidade que elas têm de tornar concreta a vivência do papel de mãe por meio da replicação de modelos copiados de outras mães, de si mesma ou de especialistas. Como ilustrado nesse estudo e outros, nota-se que o MMC facilita o desenvolvimento dessa identidade materna ao propiciar que as mães conheçam melhor o comportamento de seus bebês. Essa vivência contribui para a superação mais rápida do impacto negativo ocasionado pelo parto prematuro, reduzindo os quadros de depressão materna e a percepção de que seus bebês são anormais.23,24 Parece comum as mães-cangurus expressarem também os aspectos negativos e dificuldades relacionadas ao programa. Mais do que depor contra o MMC, essas críticas deveriam ser vistas como um sinal de sua auto-confiança, além de apontarem o grau de adequação ou não do programa.

Os efeitos positivos do MMC sobre a amamentação têm sido referidos em vários estudos. ${ }^{6-8} \mathrm{Na}$ situação brasileira, o estabelecimento pleno da amamentação é um dos critérios para alta hospitalar. Esta medida tem efeitos benéficos em curto e médio prazos, como constatado neste estudo pela redução no uso da complementação das mamadas e pela manutenção da amamentação exclusiva após a alta, porém para ser efetiva requer profissionais hábeis e mães informadas e apoiadas para superar as dificuldades. A baixa produção de leite tem sido o principal fator do desmame precoce de bebês de baixo peso, e tanto o MMC quanto as mamadas freqüentes e a ordenha precoce (até seis horas após o parto) e freqüente (pelo menos cinco vezes ao dia) das mamas têm sido associados com uma lactação mais prolongada. 25 Os nossos achados indicam uma atuação mais efetiva da equipe do Banco de Leite Humano com as mãescangurus, repercutindo sobre sua capacidade de lidar de forma apropriada com a ordenha das mamas.

Os dados coletados após a implantação do programa mostram que o critério de peso dos bebês para iniciar o MMC e para alta hospitalar é utilizado de maneira cautelosa pela equipe de saúde quando se compara a outros serviços em que o programa foi implantado.9,12 Uma possível resistência dos profissionais a encaminhar os bebês-cangurus mais cedo para casa poderia ser o desconhecimento das reais condições das famílias de baixa renda para o cuidado apropriado. ${ }^{13}$ Por isso, pode parecer temerária a revelação feita pelas mães-cangurus quanto a realizar o método em casa conforme sua conveniência. Uma explicação plausível é que a equipe de saúde tenha dado pouca ênfase à continuidade desse tipo de cuidado em casa, uma vez que os pesos na alta hospitalar se mantiveram similares aos critérios convencionais.

As características das mães-cangurus em comparação às mães antes da implantação indicam um processo seletivo do programa, no qual participam as mulheres cujos arranjos familiares são mais favoráveis. Algumas das principais barreiras para a participação efetiva das mães no cuidado do bebê de baixo peso, entre as quais a existência de outros filhos, falta de ajuda efetiva para as tarefas domésticas e a escassez de recursos para o transporte, corroboram resultados de outros estudos.13,21,22 Verificou-se que medidas que facilitaram o transporte, sejam governamentais ou de familiares e serviços de saúde, foram fundamentais para que muitas mães pudessem permanecer junto aos bebês internados. A análise relativa à ajuda nas tarefas domésticas e cuidados de outros filhos expõe o contexto atual das mulheres que vivem na periferia de uma metrópole, no qual a rede familiar de apoio é pouco presente. $\mathrm{O}$ comportamento das famílias pobres no qual prevalecem os valores tradicionais que conformam as estratégias de sobrevivência, caracterizada por uma rede familiar de malha estreita, não pode ser percebida aqui como predominante em comparação a outro estudo realizado em região metropolitana. 12 Daí a impossibilidade de muitas mães optarem pelo MMC. As mulheres da família, com quem habitualmente se podia contar como as avós e irmãs, com freqüência não moram perto, ou trabalham fora de casa.

\section{Conclusões}

Os resultados deste estudo indicam que as mães que aderiram ao MMC são aquelas cujos arranjos familiares foram mais fáceis de organizar. Por isso, as mães-cangurus são mais jovens e sem filhos.

A participação no programa aponta benefícios para a prática da amamentação, tanto pelo contato freqüente com o bebê quanto pelo maior apoio da equipe de saúde. Entretanto, ainda é necessário e possível aprimorar o programa implantado nesse hospital. Conforme experiência de outros locais, uma melhor apreensão da "filosofia" de trabalho que reina entre os membros da equipe e as chefias, assim como a avaliação periódica das práticas por meio de instrumentos padronizados que sirvam de retroalimentação do sistema, poderiam ser úteis nesse processo. 10,19,20

Algumas questões permanecem pouco compreendidas e merecem ser melhor estudadas. Até que ponto as barreiras enfrentadas pelas mães podem ser superadas com o apoio dos serviços de saúde? 
Até que ponto o maior ou menor grau de adesão das famílias são decorrentes do funcionamento do programa? O que faz com que em alguns programas implantados, tais como os do Instituto Materno Infantil Prof. Fernando Figueira (IMIP) e do Hospital Geral de Itapecerica da Serra,9,12 a participação das mães seja próximo da totalidade?

\section{Agradecimentos}

À Japan International Cooperation Agency (JICA) pelo apoio financeiro para a implantação do programa e sua avaliação. A Daisuke Onuki, educador e representante da JICA por seu empenho na viabilização da proposta. A Maria Cecília de Miranda pela organização do trabalho de campo. Às demais integrantes da equipe pelo agradável período de convivência e troca de idéias. À equipe de profissionais do hospital pela paciência e respeito que sempre tiveram conosco. E um agradecimento especial a todas as mulheres que se dispuseram a nos contar suas experiências.

\section{Referências}

1. Davanzo R. Newborns in adverse conditions: issues, challenges, and interventions. J Midwifery Womens Health. 2004; 49 (4 Suppl 1): S29-S35.

2. Martines J, Paul VK, Bhutta ZA, Koblinsky M, Soucat A, Walker N, Bahl R, Fogstad H, Costello A. Neonatal survival: a call for action, 2005. Available from: Http://image.thelancet.com/extras/05art1216web.pdf [2006 Feb 9].

3. Stening W, Roth B. Dissemination of the Kangaroo Method in Germany. J Perinatol. 1999; 19: 450-1.

4. Sizun J, Westrup B, ESF Network Coordination Committee. Early developmental care for preterm neonates: a call for more research. Arch Dis Child Fetal. 2004; 89: F384-F9.

5. Ruiz-Pelaéz JG, Charpak N, Cuervo LG. Kangaroo Mother Care, an example to follow from developing countries. $\mathrm{Br}$ Med J. 2004; 329: 1179-81.

6. Venâncio SI, Almeida H. Método Mãe Canguru: aplicação no Brasil, evidências científicas e impacto sobre o aleitamento materno. J Pediatr. (Rio J) 2004; 80 (5 Suppl): S173S80.

7. Charpak N, Ruiz JG, Zupan J, Cattaneo A, Figueroa Z, Tessier R, Cristo M, Anderson G, Ludington S, Mendoza S, Mokhachane M, Worku B. Kangaroo Mother Care: 25 years after. Acta Paediatr. 2005; 94: 514-22.

8. Lamy ZC, Gomes MASM, Gianini NOM, Hennig MAS. Atenção humanizada ao recém-nascido de baixo peso Método Canguru: a proposta brasileira. Ciênc Saúde Coletiva. 2005; 10: 659-68.

9. Lima G, Quintero-Romero S, Cattaneo A. Feasibility, acceptability and cost of kangaroo mother care in Recife, Brazil. Ann Trop Paediatr. 2000; 20: 22-6.

10. Bergh AM, Arsalo I, Malan AF, Patrick M, Pattinson RC, Phillips N. Measuring implementation progress in kangaroo mother care. Acta Paediatr. 2005; 94: 1102-8.

11. Brasil, Ministério da Saúde. Portaria n. ${ }^{\circ}$ 693/GM. Aprova a Norma de Orientação para a Implantação do Método Canguru. Brasília, DF; 2000.

12. Toma TS. Método Mãe Canguru: o papel dos serviços de saúde e das redes familiares no sucesso do programa. Cad Saúde Pública. 2003; 19 (Supl 2): S233-S42.

13. Colameo AJ, Rea MF. O Método Mãe Canguru em hospitais públicos do Estado de São Paulo, Brasil: uma análise do processo de implantação. Cad Saúde Pública. 2006; 22 : 597-607.

14. Venâncio SI, Almeida H, Miranda MCD, Martins A, Toma TS, Sanches MT, Andretto DA, Penalva O, Monteiro DSF, Folino CSG, Onuki D. Diagnóstico da evolução de recémnascidos do Hospital do Campo Limpo antes e após a implantação da Atenção Humanizada ao Recém-nascido de Baixo Peso - Método Mãe Canguru: relatório técnico, fase hospitalar. São Paulo: Instituto de Saúde; 2005.

15. Mays N, Pope C. Qualitative research: rigour and qualitative research. Br Med. J. 1995; 311: 109-12.

16. Cassiani SHB, Caliri MHL, Pelá NTR. A teoria fundamentada nos dados como abordagem da pesquisa interpretativa. Rev Latino-Am Enfermagem. 1996; 4: 75-88. 
17. Pandit NR. The creation of theory: a recent application of the Grounded Theory method. Qualitative Report [serial Internet] 1996 Dec 2 (4). Available from: http://www.nova.edu/ssss/qr/qr2-4/pandit.html [2006 Feb 14]

18. Pattinson RC, Arsalo I, Berg AM, Malan AF, Patrick M, Phillips N. Implementation of Kangaroo Mother Care: a randomized trial of two outreach strategies. Acta Paediatr. 2005; 94: 924-7.

19. Wallin L, Rudberg A, Gunningberg L. Staff experiences in implementing guidelines for Kangaroo Mother Care - a qualitative study. Int J Nur Stud. 2005; 42: 61-73.

20. Berg AM, Pattinson RC. Development of a conceptual tool for the implementation of kangaroo mother care. Acta Paediatr. 2003; 92: 709-14.

21. Furlan CEFB, Scochi CGS, Furtado MCC. Percepção dos pais sobre a vivência no método mãe-canguru. Rev Latino Am-Enfermagem. 2003; 11: 444-52.
22. Caetano LC, Scochi CGS, Ângelo M. Vivendo no Método Canguru a tríade mãe-filho-família. Rev Latino-AmEnfermagem. 2005; 13: 562-8.

23. Feldman R, Eidelman AI, Sirota L, Weller A. Comparison of skin-to-skin (Kangaroo) and traditional care: parenting outcomes and preterm infant development. Pediatrics. 2002; 110: 16-26.

24. Roller CG. Getting to know you: mother's experiences of kangaroo care. J Obstet Gynecol Neonatal Nurs. 2005; 34 : 210-7.

25. Furman L, Minich N, Hack M. Correlates of lactation in mothers of very low birth weight infants. Pediatrics [serial Internet] 2002; 109 [about 7 p.]. Available from: Http://www.pediatrics.org/cgi/content/full/109/4/e57 [2006 Jan 31].

Recebido em 5 de setembro de 2006

Versão final apresentada em 16 de maio de 2007

Aprovado em 12 de junho de 2007 